\title{
Dummett's Criticism of the Context Principle
}

\author{
Philip A. Ebert \\ University of Stirling
}

\begin{abstract}
This paper discusses Michael Dummett's criticism of the Neo-Fregean conception of the context principle. I will present four arguments by Dummett that purport to show that the context principle is incompatible with platonism. I discuss and ultimately reject each argument. I will close this paper by identifying what I take to be a deeprooted tension in the Neo-Fregean project which might have motivated Dummett's opposition to the Neo-Fregean use of the context principle. I argue that this tension does give rise to a legitimate concern, yet it does not affect the Neo-Fregean conception of the context principle.
\end{abstract}

Keywords: Context Principle, Dummett, Neo-Fregeanism, singular terms, platonism

\section{Introduction}

This paper discusses Michael Dummett's criticism of the Neo-Fregean conception and application of the context principle. In the first section, I will outline what the Neo-Fregean interpretation - defended by Bob Hale and Crispin Wright - of the context principle amounts to. In the second section, I will distinguish two strands of criticism against this interpretation and, in the following section, discuss and subsequently reject the first type of criticism. In the fourth section, I will turn to the second strand of criticism and distinguish and discuss three different arguments put forth by Dummett. I show that none of these arguments are ultimately compelling and I will close this paper by identifying what I take to be a deep-rooted tension in the Neo-Fregean project which might have been the motivation for some of Dummett's concerns. I will suggest that although it is a legitimate tension, it is wrongly levelled against the Neo-Fregean conception of the context principle.

\section{The Neo-Fregean conception of the context principle}

The Neo-Fregeans interpret the context principle primarily as a thesis concerning what determines reference of singular terms. ${ }^{1}$ Here, consider Frege's first characterisation of the context principle in the opening sections of the Grundlagen: "never to ask for the meaning [Bedeutung] of a word in isolation, but only in the context of a sentence" (Frege, 1884, x). Crudely speaking the Neo-Fregean version of the context principle is gained by replacing "word" with "singular term" and by identifying Frege's use of "meaning" [Bedeutung] with reference. What is distinctive about the occurrence of singular terms in sentences, as opposed to those same terms in isolation, is that only in the context of the former can we determine their referential potential. So, reference of a singular term is established,

\footnotetext{
1 See (Wright, 1983, chapter 1 and section $\mathrm{x}$ ), (Hale, 1987) and (Hale and Wright, 2002). For a comprehensive overview of the Neo-Fregean position, consult (MacBride, 2003).
} 
provided there is a true sentence - of the appropriate (atomic) type - in which the singular term occurs. ${ }^{2}$

This idea has various consequences but first let me make out one point of affinity between Frege's context principle and the Neo-Fregean interpretation. As noted above, Frege claims that it is part of accepting the context principle that one should not ask for the meaning of a term in isolation. On the Neo-Fregean interpretation, this claim can be understood as preventing us from asking the additional question as to whether the singular term has a referent, even if all linguistic criteria for singular termhood are fulfilled and the truth of the statement is established. Doing otherwise, is to isolate questions of existence and thus to think that further investigations would yield an answer. On the Neo-Fregean reading this additional question is, at best, superfluous, if not incoherent.

So, the context principle - as understood by the Neo-Fregeans - says that if there is a singular term occurring in a true sentence (of the appropriate type) then the term refers. Now, since the term in question is a singular term, it will refer to an object (rather than some property). As such, this principle would not be of great interest unless the additional claim is made that the criteria of singular termhood can be established without direct appeal to the object presumed to be denoted by that term. ${ }^{3}$ It is exactly this thought that is an important component in the Neo-Fregean interpretation of the context principle. The general idea is that there is a priority of linguistic questions or categories over ontological questions or categories: linguistic criteria suffice for recognising the referential potential of a term (whether it does refer obviously depends in addition on the truth and the appropriateness of the sentence it figures in). This type of "priority" of linguistic over ontological categories is further explicated in the following passage from Wright:

"By 'take priority' I mean simply this: questions of reference are not to have the independence that would make it possible to determine that a class of expressions have no genuine reference when, by the best syntactic criteria, these expressions function as singular terms in a range of statements [. . . ] which we have every reason to suppose to be true." (Wright, 1983, 25)

Hence, whether a term has referential potential (i.e. is to be regarded as a singular term which does refer if it figures in a true atomic sentence), can be established in virtue of certain syntactic criteria a term has to fulfil in order to be regarded as a singular term. This results in the idea that "the notion of an object is posterior in the order of explanation to that of a singular term" (Wright, 1983, 24). ${ }^{4}$ Crucially, this thesis which is, according to the Neo-Fregeans, tied to the context principle, puts the onus on its proponent to outline

\footnotetext{
2 In this paper, I will not be concerned with what type of sentence do qualify as "appropriate" in the relevant sense. I will assume that an adequate characterisation and motivation for this category of sentences can be given and focus on more specific criticisms by Dummett.

${ }^{3}$ For example, Field's nominalist position, e.g. (Field, 1989), is compatible with the context principle in its minimalist form. It's just that for him the relevant mathematical sentences, despite involving singular terms, do not refer since the 'appropriate' sentences are, in fact, false.

${ }^{4}$ Note that just before this passage, Wright identifies this thesis explicitly with the context principle. Similar views are later held by Wright. So, e.g. he claims one should "...treat syntactic categories, singular term and predicate, as primary in the order of explanation and the ontological categories object and concept/property as derivative.[...] But as far I can see [...] the general notion of an object remains: referent of a (possible) singular term." (Wright, 1998b, 263).
} 
specific syntactic criteria independent of the notions of reference, or object, which would suffice to identify singular terms.

In the following, I will forgo any discussion of the syntactic criteria of singular termhood 5 and simply assume that such syntactic criteria can be made out and that number terms thereby feature as singular terms.

To summarise, the Neo-Fregean conception of the context principle comprises two key thoughts:

\section{Minimal conception of the context principle}

If there is a singular term occurring in an appropriate true sentence, then this term refers and there is an object which is the referent of this term.

Note that this claim is rather minimal; no priority of linguistic categories is mentioned and no constraint on the criteria for singular termhood is in place. In addition to the minimal conception a further claim is adopted, which is motivated by the priority of linguistic over ontological categories.

\section{Syntactic Priority Thesis}

Linguistic categories have priority over ontological ones and thus the criteria for singular termhood can be established without prerequisite appeal to the objects referred to by singular terms.

The Neo-Fregeans have argued that this version of the context principle is constitutive of a new form of platonism and that it plays an important role in resolving what is known as Benacerraf's dilemma. ${ }^{6}$ Here, however, I won't be concerned with the issue of how the context principle can contribute to a satisfying answer to Benacerraf's challenge. Instead, the scope of this paper is restricted to a discussion of specific criticisms by Dummett against the Neo-Fregean usage of the context principle. That is, I will identify various arguments by Dummett that aim to show that the Neo-Fregean use of the context principle should be rejected or that it is incompatible with platonism. ${ }^{7}$

\section{Two types of criticism of the context principle}

The first type of criticism assumes that the context principle is correct but argues that if it were generally applicable, it would lead to problems since it either justifies false or contradictory statements or leads to problematic consequences in other areas of discourse. The following passage from Dummett fits nicely this first line of criticism:

\footnotetext{
5 See e.g. as proponents (Dummett, 1981a, 54-80), (Hale, 1979), (Hale, 1995) (Hale, 1996) (Wright, 1983, 10-12 and 53-64). For an overview of criticism, see (MacBride, 2003) and more specific criticism (Williamson, 1988) and (Wetzel, 1990).

6 This point is already made in (Wright, 1983), yet it takes centre stage in (Hale and Wright, 2002). Similar ideas are critically discussed in (Rosen, 1993) and in (MacBride, 2003). Benacerraf's dilemma is outlined in (Benacerraf, 1973).

7 Concerns not discussed in this paper are, for example, the issue of impredicativity, see (Dummett, 1991, 236) and (Dummett, 1998), and the reductive character of abstraction principles, see (Rosen, 1993) and (MacBride, 2003).
} 
"the contradiction was a catastrophe for Frege, not particularly because it exploded the notions of class and value range, but because it showed that justification [i.e. the context principle] to be unsound. It refuted the context principle, as Frege has used it." (Dummett, 1991, 225)

In the next section I will discuss in detail one version of this criticism as put forward by Michael Dummett.

The second type of criticism aims to show that the context principle is incompatible with platonism. Crudely put: Dummett argues that the minimal reading of the context principle plus the syntactic priority thesis entail the claim that so-called pure abstract objects (such as numbers, sets, etc.) whose reference is established by the context principle, exist mind- or language-dependently. Thus, one cannot interpret the first two theses as justifying "real" reference to pure abstract objects. Rather, according to Dummett, we can only adopt some kind of "thin" reference, which will be insufficient for a platonist. In effect, Dummett aims to show that there is an irresolvable tension between adopting the context principle on the one hand, and resolving Benacerraf's challenge via the platonist route on the other. If Dummett is correct, the Neo-Fregeans are deeply misguided in thinking that the context principle can provide the basis for a platonist conception of mathematics.

\section{The first type of criticism: The legitimating role of the context principle}

Dummett has claimed on various occasions that the context principle should be rejected because of the inconsistency of Basic Law V. Consider, e.g., the following two passages:

"What mattered philosophically, however, was not the definition in terms of classes, but the elimination of appeals to intuition, a condition for which was the justification of a general means of introducing abstract terms, as genuinely referring to non-actual objects, by determining the truth-conditions of sentences containing them. The contradiction was a catastrophe for Frege not particularly because it exploded the notion of class and value-range, but because it showed that justification to be unsound. It refuted the context principle, as Frege had used it." (Dummett, 1991, 225)

"For Frege's method of introducing the abstraction operator - that is, of introducing value ranges - was, notoriously not in order. It rendered his system inconsistent; and that inconsistency forced him eventually to acknowledge that his entire enterprise had failed. If the context principle, as stated by Wright, were sound, there could have been no inconsistency." (Dummett, 1991, 88), italics in the original.

Let me briefly explain this last quotation: Frege's method of introducing the abstraction operator is the idea that abstraction principles introduce functions which, in the case of 
conceptual abstraction principles, are functions from properties to objects. ${ }^{8}$ Frege's infamous Basic Law V is meant to introduce the value-range operator which maps coextensive properties (or: functions that map every object to the same value) to the same value-range. As is well-known Basic Law V is inconsistent.

The main thought in these two quoted passages seems to be that the fact that BLV turned out to be inconsistent raises problems for the general application of the context principle. Disregarding for the moment possible differences in the context principle as Frege used it and as stated by Wright, Dummett's thought seems to be that the context principle justifies or legitimates abstraction principles in general. So, if on the basis of such justification an instance of such abstraction principles turns out to be inconsistent, then there is something wrong with its initial justification, namely the context principle. Hence, roughly we have the following short piece of reasoning: (1) The context principle legitimates the introduction of abstraction principles. (2) Some abstraction principles (e.g. Basic Law V) are inconsistent. Thus, (3) the context principle is defective as a legitimation for abstraction principles.

As it stands, this reasoning needs clarification and disambiguation. Let me outline two ways in which the idea of justification or legitimation can be understood and analyse why one might think that (1) is correct. On the first reading, the Neo-Fregeans use the context principle within the context of abstraction principles so that to be credited with an understanding of the new term - such as "the (cardinal) number of" in the case of Hume's Principle or "the value-range of" in the case of Basic Law V - it suffices to grasp the relevant abstraction principle. If the abstraction principle is successful, it fixes truthconditions of the identity statements in which the new expression figures by means of already understood terms that occur on the right-hand side of the abstraction principle. Now, if legitimitation is understood in just this sense - i.e. what the context principle legitimates is that to be credited with an understanding of a new term grasping the relevant abstraction principle is sufficient - then this type of legitimation is not yet sufficient to provide a guarantee that abstraction principles, in general, are consistent. This reading of legitimation is concerned with the role of abstraction principles for a subject's understanding of a new term but not with whether the abstraction principle itself is consistent. Hence, this type of legitimitation is not intended to effect the consistency of the underlying abstraction principle; nor, is it prima facie necessary that the abstraction

8 The general form of an abstraction principle is:

$$
\forall a \forall \beta(\xi(a)=\xi(\beta) \leftrightarrow a \approx \beta)
$$

where $\xi$ is a term-forming operator applicable to expression of the type of $\alpha$ and $\beta$ and $\approx$ is an equivalence relation on entities denoted by expressions of that type. If $a$ and $\beta$ stand for singular terms, the resulting (objectual) abstraction principle is first-order. If they stand for first-order predicates the resulting (conceptual) abstraction principle is second-order. An example of a firstorder or objectual abstraction principle is the Direction Abstraction:

The direction of line $a$ is equal to direction of line $b$ if and only if line $a$ is parallel to line $b$

Hume's Principle, a principle which embedded in standard second-order logic yields the Peano axiom and so arithmetic, is a second-order or conceptual abstraction:

$$
\forall F \forall G((N x: F x=N x: G x) \leftrightarrow(F \approx G))
$$

where "Nx : Fx" stands for "the (cardinal) number of F's" and " $\approx$ " expresses the equivalence relation of equinumerosity. Another example for conceptual abstraction principles is Frege's infamous Basic Law $V$, introducing the value-range operator $(V R)$ :

$$
\forall F \forall G(V R: F=V R: G \leftrightarrow \forall x(F(x) \leftrightarrow G(x))) .
$$


principle has to be consistent in order to provide an understanding of the new term involved. It might well be argued that even inconsistent abstraction principles can provide an understanding (albeit incomplete) of a new term. ${ }^{9}$ If correct, the issue of consistency is independent of this type of legitimation and the argument is not compelling: it cannot be the aim of the intended legitimitation to guarantee the consistency of an abstraction principle.

On the second reading we interpret the type of justification and legitimation the context principle offers as providing a guarantee that the new terms introduced in virtue of abstraction principles occur in true and thus consistent abstraction principles. This understanding of the context principle would make the occurrence of inconsistent abstraction principles very problematic indeed and so, the above reasoning would make a rather compelling point. ${ }^{10}$

However, it is unclear why the context principle as previously outlined, i.e. the minimal reading and the syntactic priority thesis, should be regarded as comprising this strong sense of legitimitation. The minimal reading of the context principle merely says that if there is a singular term occurring in a true sentence (of the appropriate type) then there is an object as the referent of that term, and as such it cannot provide a guarantee that the abstraction principle is true. The second component of the context principle - the syntactic priority thesis - cannot provide such a guarantee either. It merely claims that linguistic criteria have priority over ontological ones. Consequently, the context principle has no bearing on whether abstraction principles are true (and thus consistent) or not. ${ }^{11}$

To summarise, the context principle does not itself have any direct bearing on the truth of individual abstraction principles; the context principle only has an effect in that it guarantees reference of singular terms, provided the abstraction principle, in which the

\footnotetext{
9 Examples are Basic Law V, or the (unrestricted) T-schema for 'true'. To be sure, I'm not claiming that every inconsistent statement has a graspable content. It is enough - for current purposes - to point to some principles that despite their inconsistency provide some kind of understanding of the relevant term. This point is further developed in (Ebert, forthcoming). Also compare Frege's remark Grundlagen: "A concept is admissible even if its characteristic marks contain a contradiction." (Frege, 1884, 105).
}

10 For instance, in a similar fashion to Dummett, Kit Fine argues against the context principle. In his book Limits of Abstraction he dedicates a chapter discussing the principle as used by the NeoFregeans. Therein, he supposes that 'the 'context principle' can be regarded as an attempt to vindicate such contextual definitions." (Fine, 2002, 55). (In this quotation 'contextual definitions' can be understood as involving abstraction principles.) Just as in the case of Dummett, it is unclear in Fine's writing to what extent the context principle is supposed to justify or vindicate such definitions. On various occasions, however, Fine seems to have a rather strong reading in mind. He regards the context principle as providing a justification that the abstraction principle so introduced is true. For a similar point against Fine, see (Cook and Ebert, 2004, 798ff).

11 This is not to say that the method that Wright uses in (Wright, 1983) is without its problems: Wright's apparent unqualified assumption is that the introduction of an abstraction principle suffices, in all cases, to fix consistent truth-conditions for the relevant identity-statements. Surely this is objectionable, and it has since led to extensive discussions under the guise of so-called Bad Company objection: the challenge to provide appropriate conditions for good abstraction principles. My point here, however, is that this concern can be separated from the intelligibility of the context principle and so it cannot be used as a reductio on the context principle as outlined here. 
singular term occurs, is true. So, the the first kind of criticism levelled against the NeoFregean conception of the context principle fails to be compelling. ${ }^{12}$

\section{The second type of criticism}

In contrast to rejecting the application of the context principle altogether, Dummett also suggests that one could maintain the principle "but declare that it does not vindicate the procedure Wright has in mind." (Dummett, 1991, 205). And here, what "Wright has in mind" is the thought that the context principle suffices to impose 'robust' or 'real' reference to abstract objects, such as numbers. In opposition to Wright, Dummett also believes that the context principle fails to guarantee a genuine reference relation to something existing independently. In the following, I will outline and discuss three separate lines of arguments in Dummett's writing that aim to undermine a 'realistic' or robust interpretation of the reference relation for abstract terms as introduced by the context principle. ${ }^{13}$

\subsection{The argument from disanalogy}

Dummett motivates a disanalogy between how we normally learn the use of singular terms purporting to refer to concrete objects and those that "seem" to refer to abstract objects. ${ }^{14}$ The idea is roughly the following: In the concrete object case, we establish the reference of a term by the so-called name-bearer prototype, in which intuition - that is a perception of an object or a cognitive encounter with the object - plays a direct role in the identification and re-identification of the referent of the term. So, according to Dummett, to manifest an understanding of a newly introduced term purporting to refer to a concrete object is to exhibit the ability to identify the referent of this new expression - for example by understanding demonstrative phrases in which the new term occurs. ${ }^{15}$

In clear disanalogy, Dummett contends that this kind of manifestation does not seem to be possible for expressions purporting to refer to abstract objects. The role of the referent is minimised and it seems impossible - just because the object is abstract - to use the name-bearer prototype to establish a reference relation for the term. So, to manifest an understanding of this new term does not involve an appeal to the object purportedly referred to.

Based on this disanalogy, Dummett concludes that abstract terms do not have genuine reference (i.e. reference to something externally existing). The inference to this

\footnotetext{
12 This is, of course, not to say that Frege's original use of the context principle is unaffected by Dummett's criticism. I here focus only on a Neo-Fregean conception of the context principle and leave Frege scholarship for another occasion.
}

13 The relevant sections of Dummett are (Dummett, 1981a, chapter 7 and 14), (Dummett, 1981b, chapter 18, 19 and 20), and (Dummett, 1991, chapters 15-18).

14 Dummett notes the disanalogy in (Dummett, 1981a, 494) in the context of Goodman's nominalism. The use of the disanalogy as an argument is on (Dummett, 1981a, 499) and most explicitly in (Dummett, 1981a, 505). It reappears, using slightly different vocabulary, in (Dummett, 1998, 384ff).

15 Dummett is, of course, aware of Wittgensteinean consideration that mere ostensive definitions could not establish this relationship. However, Wittgensteinean worries will be left untouched in my discussion. 
conclusion is supported by the claim that intuition has to play a certain role in the identification of the referent for there to be a genuine reference relation to something external; and if it does not, the term has no genuine referential relation to something external. Differently put, for the case of abstract terms the role of reference is semantically idle as the referent does not play a role in determining the truth-value of statements in which it figures, i.e. no intuition is involved in determining the truth-value of statements involving the new term. Therefore, no real reference can be assumed for abstract terms. In contrast, the role of reference in the case of terms standing for concrete objects is semantically operative in that intuition is essential in manifesting an understanding of the term. A version of this argument can be found in the following passage by Dummett:

"I proposed for a notion of reference for singular terms to be robust enough to support a realistic interpretation [. . . ] that their reference should be semantically operative. Whether a notion of reference for terms of a given range is semantically operative or semantically idle depends on the sense we attach to the sentence containing a term of that range. In grasping its sense, we have a conception of the way in which its truth-value is determined. If the determination of the truth-value of any such sentence goes through the identification of the referent of the term, the notion of reference, as applied to it, is semantically operative; if it does not that notion, even though legitimate, is semantically idle." (Dummett, 1998, 385) my italics, see also (Dummett, 1991, 239)

And in a further (and earlier) passage Dummett again makes a similar point:

"But precisely the point at which the analogy fails is in the use of the realist picture: the recognition of the truth of a numerical equation cannot be described as the identification of an object external to us as the referent of a term, precisely because there is no sense in which it requires us to discern numbers as constituents of the external world." (Dummett, 1981a, 505)

The conclusion Dummett aims to draw from this is not that no reference to abstract objects can be assumed, which would be to support a form of nominalism that Dummett previously rejected. Instead, we merely cannot assume robust reference - reference to an independently existing entity - in the case of terms introduced in virtue of contextual definition (or abstraction principles).

Consequently, Dummett introduces a less substantial "thin" notion of reference on the grounds that there is a clear disanalogy between prototype cases of how reference functions in concrete cases and cases where abstract objects are involved. Compare the following quotation from Dummett concerning the reference of new terms introduced in virtue of contextual definitions:

"In such a case [of contextual definition], no view stronger than an intermediate one could be taken of a claim that a reference had thereby been conferred upon them [i.e. the new terms]; the reference so conferred would be reference only in the thin sense [... ], since the notion would play no role in the semantic account of how the truth-values of sentences containing the terms are determined." (Dummett, 1991, 236) ${ }^{16}$

\footnotetext{
${ }^{16}$ See also the following passage: "The proponent of the intermediate view of terms introduced by contextual definition - the view for which I have here argued - maintains that the thin notion of reference will not bear the weight of a realistic interpretation of those terms;" (Dummett, 1991, 198)
} 
As it stands, I believe that Dummett's argument from disanalogy can be challenged on at least three grounds:

1. Grant the disanalogy but show that something else can be regarded as fulfilling the role of the name-bearer prototype in the abstract case, which thereby guarantees a real reference relation for abstract terms.

2. Challenge Dummett's crucial transition from the claim that intuition is not necessary for manifesting our understanding in the case of abstract singular terms to the claim that therefore they do not refer realistically.

3. Challenge the coherence of Dummett's own proposal concerning "thin" reference.

The first line of response has been pursued by Wright ${ }^{17}$, but I will leave a detailed discussion of this strategy aside. I believe that this discussion ends in a stand- off between Dummett and Wright and as such won't be sufficient to undermine Dummett's argument. Instead, I will focus on what I think is wrong with Dummett's argument by focusing on the second strategy and then raise some doubts about the coherence of his position by pursuing the third strategy.

\subsubsection{First rejoinder: Dummett's illicit inference}

In order for Dummett's argument from disanalogy to have force he requires a strong assumption, which consists in moving from the role an object plays in our understanding of the term referring to it, to conclusions about its ontological status. More precisely, Dummett's argument starts out with the intuitive claim that in the case of concrete objects where we do have real reference, intuition plays a crucial role in manifesting our understanding and thereby settling the reference of a term. In the case of abstract terms, intuition does not play any such role in our understanding of the term, a point that again is intuitive. But from this, Dummett draws the ontological conclusion that the object referred to does not exist externally, i.e. mind-independently. However, what is it that underwrites such a transition? I think that the transition cannot be upheld in general. In order to highlight my worries consider the following two questions: ${ }^{18}$

1. Do we need intuition to justify or manifest that we understand new terms figuring in certain sentences (say sentence S)?

2. Do the objects referred to by the new terms involved in the sentence S exist mindindependently?

If I understand Dummett correctly, he seems to be committed to answering the second question with "no" provided that he returns a negative answer to the first. But I find it hard to detect a compelling reason to think this being correct. Consider, for example, sentences in modern theoretical physics involving mainly theoretical terms (such as "strings", "neutrinos", etc.) or other theoretical terms such as "the equator", "the north pole". In this case, manifesting our understanding of such terms does not seem to involve any intuition in the sense of having a perception of the object or a cognitive encounter with it. And yet the lack of this type of encounter does not seem to have any bearing on the ontological

17 Compare here (Wright, 1983, section $\mathrm{x}$ ).

18 The distinction I am about to make is similar to one made by (Hale, 1987, 165ff). 
status of the objects involved. As a result, I regard the general application of this transition as questionable at best; and so the onus is on Dummett to provide some reasons why there is such a strong link between these two issues.

However, there may be a weaker reading of the argument, namely, that based on the disanalogy, the default reason to think that abstract terms refer realistically is lacking. Hence, unless there is independent reason to think otherwise - and arguably in the physics case there is - we should conclude that such terms do not genuinely refer to mindindependent objects. ${ }^{19}$

Even granting this much, I think that, dialectically, some reason for making the transition from understanding a term to the ontological status of the object referred to is required. Otherwise it is unclear why the name-prototype is a default reason for mindindependent existence. Furthermore, the platonist might well be credited with having independent reasons for thinking that numbers and sets exist mind-independently. So, for example the belief that mathematical truths are necessary could give rise to the belief that the objects referred to are mind-independent. Either way, Dummett's argument seems to involve an unmotivated assumption and even the more favourable version of the argument can be challenged.

Thus, let me now turn to the conclusion of Dummett's argument from disanalogy and challenge the coherency of his own conception of "thin" reference.

\subsubsection{Second rejoinder: Some scruples about "thin" reference}

Dummett claims that there is a type of reference - "thin" reference - which is a genuine reference relation, even though it lacks the realistic underpinnings of robust reference. Dummett says very little about the characteristics of this notion of reference. The aim of this section is to suggest different ways of interpreting "thin" reference and to raise doubts as to whether Dummett is entitled to claim that "thin" reference is a genuine reference relation.

First, let us investigate why Dummett thinks he is entitled - within his framework - to assume that abstract terms actually do refer, but merely "thinly". As noted, Dummett regards robust reference as a relation that only holds if it is embedded in intuition and in this way the term becomes semantically operative. But then, if there is no intuition and nothing else in which the reference relation is embedded, on what grounds can Dummett maintain that when the terms are not semantically operative (i.e. they are semantically idle), there still is a genuine, yet only "thin" reference relation? Why isn't it the case that these are non-referring terms?

To highlight this problem, let me put forth the following dilemma for the Dummettian position: Either he offers an alternative to intuition which underwrites the reference relation in the case of abstract terms; but then it could be argued - along the first line of response which I did not discuss in any detail - that these grounds suffice to ensure "real" reference and not merely "thin" reference. Or, alternatively, Dummett does not provide an alternative to intuition, which would then open up the option to reject any type of reference relation even "thin" reference.

\footnotetext{
19 I knowingly pass over agnosticism as an alternative conclusion. It seems to me that, at best, Dummett's arguments only give rise to agnosticism.
} 
Here, I will leave this dilemma as an open challenge, and turn to the issue of disambiguating various interpretations of Dummett's notion of "thin" reference. The aim is to clarify what exactly it is that is supposedly "thin" about this sort of reference. Two possible interpretations can be considered.

1. That the relation of reference is somehow itself "thin" or deflated.

2. The referent, i.e. the object referred to, is "thin" in some sense.

Concerning the first interpretation the question is what it is for the relation itself to be "thin". I will suggest three ways this could be made sense of. One possible interpretation is that "thin" reference for abstract terms means that the relation holds at best

indeterminately. ${ }^{20}$ However, usually the idea of indeterminate reference is not regarded as in any way less "substantial" than the normal one. It is normally regarded as still picking out (albeit indeterminately) independently existing objects. So, it seems that Dummett's conception of "thin" reference has to be understood differently.

The second suggestion results from unpacking a quote from Dummett:

"The context principle, as understood in the Grundlagen, therefore admits only a thin notion of reference, that notion according to which "The direction of a" refers to something' is indisputable true, because it reduces to 'The line a has a direction', and "'The direction of a" refers to the direction of a', [is] trivially true, because it reduces to 'The direction of $a$ is the direction of a'. The context principle of the Grundlagen is thus strictly analogous to the redundancy theory of truth according to which "Cleanliness is next to godliness" is true' reduces to 'Cleanliness is next to godliness."' (Dummett, 1991, 195)

Now, this disquotational conception of "thin" reference can be combined with other theses that Dummett held, namely: (i) we have to have the resources to distinguish referring and non-referring terms in the object-language; (ii) the tolerant reductionist view that "our grasp of the thought expressed by a sentence containing the term is mediated by our knowledge (possibly only implicit) of how to arrive at an equivalent sentence not containing that term." (Dummett, 1991, 193) If we combine these ideas, then we arrive at the conclusion that a reductionist can tolerate someone saying - in the object language - that certain entities (such as directions) exist, even though our meta-linguistic account of them uses other entities (lines). Thus, there is, strictly speaking, no commitment to directions and in that sense we merely have a "thin" reference relation.

The main difficulty with this interpretation, however, is that it seems highly questionable whether "thin" reference so understood is not just a denial of a genuine reference relation altogether. After all, it reduces merely to a disquotation-device and we are left wondering whether there is a relation that holds between the term "direction" and the object (direction). It seems to me that this interpretation comes very close to reading "thin" reference as involving no reference at all: reference is here a mere façon de parler. ${ }^{21}$

20 See for example (Fine, 1975) where he provides a formal framework, i.e. supervaluationist semantics for indeterminate reference.

${ }^{21}$ An allusion to the following passage in Dummett: "[Frege's] 'context' doctrine of meaning may be accepted as an explanation and defence of the use of abstract terms, but reference may be ascribed to them only as a façon de parler." (Dummett, 1981a, 508) 
A similar concern applies to the third suggestion, which can be extracted from earlier writings of Dummett. In his Frege: Philosophy of Language he distinguished two types of reference relations, normal or name-bearer prototype reference and reference as semantic role. Might the latter be of help interpreting his later notion of "thin" reference - this despite the fact that Dummett never explicitly identified them? ${ }^{22}$ The difference between the two notions is that the normal (or prototype) reference is regarded as a relation between a term and something extra-linguistic, whereas reference as semantic role is defined by the contribution the expression makes to the determination of the truth-value of sentences in which it occurs. ${ }^{23}$ We are once again left with a conception of reference where there is no genuine reference relation. In fact, Dummett's notion of reference as semantic role seems very close to the notion of a Fregean sense. 24

A more promising interpretation might be to think of the notion of "thin" as applying to the referent and not to the reference relation. Consequently, to invoke the idea of "thin" reference is another way to say that abstract terms refer, but the objects referred to are somehow "thin". If that is the right way of looking at Dummett's notion of "thin" reference, and if, as I argued, the argument from disanalogy fails, then an alternative argument is needed to establish the ontological claim that abstract terms refer to mere "thin" objects. In the next section, I discuss such an argument. 25

\subsection{Pure abstract objects and the argument from analyticity}

Dummett's second argument is based on a distinction about the nature of objects. He distinguishes abstract objects in general from what he calls pure abstract objects. Examples of the former type are objects to which terms refer that have been introduced contextually by means of abstraction principles involving concrete objects on their righthand side, as in the case of directions. ${ }^{26}$ Other examples that are mentioned in the literature involve terms that are introduced by a demonstrative combined with a so-called functional expression. ${ }^{27}$ Pure abstract objects, in contrast, are characterised as those

22 Dummett's discussion of reference as semantic role took place 20 years earlier in (Dummett, 1981a, 204-45). Hale (Hale, 1987) and Wright (Wright, 1983) often used the idea of 'reference as semantic role' as an interpretation of "thin" reference.

${ }^{23}$ See for example (Dummett, 1981a, 210f).

24 To strengthen the exegetical suggestion that Dummett's reference as semantic role is similar to the notion of Fregean sense requires a more detailed investigation. I will, however, postpone further discussion of this point to another occasion.

25 Dummett's notion of "thin" reference has been discussed in the literature. For example, (Hale, 1994), (Wright, 1998a) and (Wright, 1995). The discussion below, however, is independent of the previous debate.

26 See footnote 8 for further details on the direction abstraction principle. However, note that not all objectual abstraction principles will give rise to abstract objects. Some might give rise to pure abstract objects, see e.g. Hale's difference-pairs abstraction in (Hale, 2000).

${ }^{27}$ An example of a functional expression is the notion "shape", which can be introduced with the statement "the shape of this figure" accompanied with an appropriate pointing gesture. See Dummett on "functional" expressions in (Dummett, 1981a, 176-9). To stress, the above examples for abstract objects are just that, examples, and not intended as providing necessary and sufficient conditions. The exact conditions need not concern us here. 
"whose existence may be recognised independently of any concrete object, and therefore independently of any observation of the world." (Dummett, 1981a, 504), my italics. And for Dummett these are objects to which terms refer that are introduced in virtue of secondorder abstraction principles, where one does not abstract on objects but on concepts, as is the case of Hume's Principle. ${ }^{28}$ On another occasion, Dummett characterises pure abstract objects as those "whose existence is analytic."(Dummett, 1981a, 505).29

Let us grant Dummett the distinction between abstract and pure abstract objects. What he aims to show is that pure abstract objects cannot be "constituents of an external reality". One argument in which the notion of a pure abstract object seems to play a role is in the following quotation:

"..., but for, say, shapes of physical bodies the sequences of concrete objects, the use of these terms is still clearly related to processes of observation of the external world and identification of constituents of it. For that reason, therefore, it is still possible to apply to such terms the notion of reference, construed realistically as a relation to something external; although, indeed, the further we travel along the scale, the more stretched becomes the analogy with the prototypical case. It is only when we reach terms for pure abstract objects, however, that the thread snaps completely, and we are concerned with the use of terms which have no external reference at all." (Dummett, 1981a, 510)

There are at least two readings of this remark. The first is one in which the "snapping of the thread" is due to the fact that the prototypical case of reference does not apply and so we are back at the earlier argument from disanalogy. The second reading, however, assigns the notion of a pure abstract object a distinct role in arriving at the conclusion that pure abstract singular terms do not have external reference. In a previous section, Dummett mentions the following additional consideration about pure abstract objects which might support this reading:

"But the picture does seem to require that what may be called a 'constituent of reality' is something which can be encountered; and, if the existence of something is an analytic truth, a recognition of its existence can hardly be held to constitute an encounter." (Dummett, 1981a, 503)

Combining this thought with the first quotation, we can reconstruct the following argument from analyticity:

Premise 1 In order for a term to have external reference, minimally, the object it purports to refer to has to be a 'constituent of reality'.

Premise 2 For an object to be a constituent of reality it has to be encounterable in some sense.

${ }^{28}$ Again see footnote 8 for further details on Hume's Principle.

29 I assume what Dummett here means is that an existential statement involving such objects is an analytic truth. See also below. 
Premise 3 Objects whose existential statement is an analytic truth are not encounterable in any relevant sense. ${ }^{30}$

Conclusion "The thread snaps": pure abstract terms do not have reference to an external object.

Now, since the argument is aimed at a platonist, we need to be careful in interpreting load-bearing notions involved such as "constituent of reality" and "encounterable". It would be question-begging to take "constituent of reality" in premise 1 and 2 to require that such a constituent has to be spatio-temporally located. Furthermore, Dummett's notion of "encounterable" cannot just be understood to mean "perceivable by a subject" or "capable of causal interaction". Consider, for example, premise 3 and assume with Dummett that numbers are objects whose existence is analytic. That is, according to Dummett, we recognise their existence without encountering them. Certainly, if "encounterable" is here understood as "capable of causal interaction" then premise 3 could well be regarded as true (even by the platonist), yet premise 2 will beg the question. So, in order to run the argument without begging the question, what is needed is an interpretation of the notions "constituent of reality" and "encounterable" which avoids these problems. In addition, we need an understanding of these notions which allows abstract objects but not pure abstract objects to be encounterable or to be constituents of reality. This latter constraint is needed in order to respect Dummett's rejection of nominalism. I find it hard to offer any suitable understanding of these notions which respects the above constraints. Given this, I will leave it as an open challenge for the Dummettian to come up with a suitable interpretation and thus (tentatively) conclude that the argument from analyticity fails to be compelling at this stage.

\subsection{The argument from conceptualisation}

A further argument, that I will label the argument from conceptualisation, can be found in Dummett's work. ${ }^{31}$ The following quotation provides the gist of the argument:

"When we apply the conceptual apparatus with which language supplies us to reality, this results in the discernment of a variety of objects, con-crete and abstract: but the apparatus is such that certain objects will be recognised however the reality is constituted to which we apply it; these are pure abstract objects, like the natural numbers, whose existence is analytic. This is incomprehensible if we think of the world as composed of objects, as coming to us already segmented into objects: in that case, how could there be a whole plurality of eternally existing, uncreated objects? But, once we realise that our apprehension of reality as decomposable into discrete objects is the product of our application to an unarticulated reality of the conceptual apparatus embodied in our language [1], it should not be particularly surprising that certain objects should result from this operation no matter what the reality is like [2] to which it is applied.

\footnotetext{
30 I simplified this point. Dummett talks about "a recognition of its existence" not involving an encounter; but I assume that this entails, in general, that recognising their existence cannot involve an encounter.

31 Interestingly, it disappears in his later writings although the argument plays an important role in the chapter entitled Abstract Objects in (Dummett, 1981a).
} 
Perhaps not: yet for that reason it appears impossible to regard the pure abstract objects as constituent of an external reality [3]." (Dummett, 1981a, 504-5) my additions.

Again, I will try to transform this reasoning into a more perspicuous three step argument, followed by a brief discussion of Hale's reply to the argument and my own evaluation of the various points raised.

The first premise [1] is Dummett's claim about how the structure of language shapes our apprehension of reality. It is what I call the Objects qua Conceptualisation Thesis $(O C T)$ :

Premise 1 (OCT) The apprehension of reality as having distinct objects is dependent upon the usage of the conceptual apparatus supplied by language. ${ }^{32}$

This premise is somewhat vague. It is not clear what exactly this dependence amounts to. Furthermore, note that what is claimed is not that the existence of objects is somehow dependent upon our language - a precariously strong claim - but rather that our apprehension of reality as having objects depends upon our conceptual scheme. Also, Dummett thinks this premise follows directly from the adoption of the context principle (more on this below).

The second point [2] Dummett makes is a restriction to pure abstract objects.

Premise 2 Certain objects may "result" from the operation of conceptualisation alone, i.e. no matter what reality is like.

Again, this premise needs some sharpening. I shall abandon Dummett's modal talk and assume that his point in premise 2 is that, in fact, certain objects, such as pure abstract objects, result solely from operations of conceptualisation. Interestingly, this premise seems not to concern our apprehension of such objects as resulting from conceptualisation but suggests that it is the objects themselves that result from these operations of conceptualisation.

Lastly, putting the two premisses together, Dummett arrives at the conclusion:

Conclusion Pure abstract objects are not constituents of an external reality.

There is much to say about the argument. On first sight, it seems as if various steps are missing in order to arrive at the conclusion. One thought might be that there is something similar in play as in the previous argument from analyticity: Because certain objects result from conceptualisation and their existence is "analytic", it follows that they cannot be constituents of an external reality. However, there is another interpretation of Dummett's argument which is independent of the above argument from analyticity and which has been discussed by Hale.

\footnotetext{
32 Similar expressions of the same thought are "what objects we recognise the world as containing depends on the structure of our language" (Dummett, 1981a, 503), "it is we who, by the use of language,[. . . ] impose structure on it."(Dummett, 1981a, 504) and "it is only because we employ a language [... ] that we learn to slice the world up, conceptually, into discrete objects." (Dummett, 1981a, 407).
} 
Hale's strategy is to show that Dummett relies on an implicit assumption for the argument to go through. By highlighting it, he offers a new interpretation of the structure of Dummett's argument. To reveal this assumption, he questions what exactly restricts the denial of an external reality to pure abstract objects and why does it not apply to impure abstracts or even concrete objects. The reply on behalf of Dummett is stressing premise 2, namely that pure abstract objects result solely on the basis of our conceptual apparatus and no matter what the reality to which we apply it is like. However, Hale questions why this should constitute a relevant difference and concludes that there is a relevant difference only if the following additional claim is adopted. Hale writes:

"It would be so [i.e. that there would be a relevant difference], if it were assumed that, for objects of some kind to be constituents of an external reality, their existence must be a contingent matter - that is, it must depend upon just how the world is, as a matter of fact, in respects to which it could have been otherwise." (Hale, 1987, 157)

So, premise 2 makes a relevant difference only if the additional thesis, call it Mindindependent Existence is Contingent (MEC), is assumed:

"For objects to exist externally, i.e. mind-independently, their existence must be a contingent matter, i.e. it is dependent on how the world is and thus could have been otherwise." (Hale, 1987, 157)

Given this the argument seems in better shape. Yet, Hale argues that (MEC) is implausible because it relies in turn on another, even more problematic assumption. He writes:

But why make this assumption [MEC]? Well, that would, it seems, be a fair assumption, if, but only if, it were the case that all necessity is of our making - the inevitable, but metaphysically innocuous byproduct, as it were, of our efforts of conceptualisation. In short, if this diagnosis of the underpinnings of Dummett's argument is correct, its capacity to undermine platonism depends, after all, upon the tenability of some sort of conventionalist reduction of necessity. (Hale, 1987, 157)

Hale's interpretation is revealing but some further questions remain. First and foremost, what role exactly does OCT (premise 1) play in the original argument? The following reconstruction based on Hale's interpretation seems valid as a self-contained argument:

Premise 1* MEC For objects to exist externally, i.e. mind-independently, their existence must be a contingent matter.

Premise 2* Certain objects, such as pure abstract objects "result" from the operation of conceptualisation alone, i.e. no matter how the reality is like and thus exist necessarily.

Conclusion Pure abstract objects do not exist externally and so do not exist mindindependently.

So, MEC, plus the thought that pure abstract objects exist necessarily, are already sufficient for the conclusion and thus premise $1-$ i.e. OCT - is irrelevant.

Second, it is not clear that adopting a conventionalist view on necessity is necessary and sufficient for MEC. It seems possible to adopt MEC and reject the conventional 
character of necessity and, conversely, it seems equally possible to adopt a conventionalist account of necessity and reject MEC. Only if the additional thesis is adopted that the metaphysical status of a kind of object (as being mind-dependent or mind-independent) just is a question about the metaphysical status of truths about these objects, can a link be established between the two claims. It is noteworthy that Hale explicitly adopts this additional thesis throughout his discussion. He writes, "what is required for those objects to be 'external' or constituents of a mind-independent reality [...] is best seen as, at bottom, a question about the (metaphysical) status of the truths of the corresponding sort - viz. do these truths hold independently of us/of our thought and talk?" (Hale, 1987, 165). Here, I do not want to deny this link but rather point out that there is logical space for alternative views.

More importantly, let me offer some evaluation of Dummett's argument. First, if it relies on MEC, then I think it should be rejected. So, for example, according to MEC, it is a necessary condition for an object to exist mind-independently that its existence is a contingent matter. So, to take the example of God: Assume that if God were to exist, he would exist necessarily, but then, according to MEC, he would have to exist minddependently. Also on this conception, pure sets, i.e. sets without individuals in the transitive closure of the membership relation, would exist mind-dependently. Yet, it remains open whether objects such as impure sets, such as the singleton of some contingent object, which, at least prima facie is a contingently existing abstract object, exists also mind-independently. Thus, MEC is highly questionable.

The following suggestion which might help to provide some motivation for an alternative explanation of Dummett's reasoning. It may be derived from the "artefact of the model" metaphor as defended by Stewart Shapiro:

"Typically, some features of a given mathematical model correspond to features of reality that is being modelled and some do not. The latter are called artefacts of the model, and let us call the former 'representors'. In a point-mass model of a physical system, the co-ordinate system, the units of measure and the notation for numbers are artefacts of the model. They do not correspond to anything in real physical systems. The metric and various relationships between forces and distances, like the inverse-square principle, are representors, not artefacts. Notice that, in a given case, it may not be clear what is representor and what is artefact and perhaps the boundary is not sharp." (Shapiro, 1998, 139).

We could apply this idea to Dummett's writing in the following way: Namely, certain objects, such as pure abstract objects, that come about "no matter how reality is like" are in this respect mere "artefacts of our conceptualisation". They come about through conceptualizing and are artefacts and not representors. As a result they cannot be regarded as existing genuinely mind-independently. Maybe it is a consideration like this that underlies Dummett's argument from conceptualisation.

However, even if that is so, Dummett has not yet explained why, adopting this talk of artefacts in the case of pure abstract objects, these kinds of objects would qualify as genuine artefacts. More precisely, he has to explain away the alternative account of why pure abstract objects always exist in any conceptualisation: It is just because objects such as pure abstract objects do exist necessarily and mind-independently! That is, a correct and complete conceptualisation of the world will always have to involve such objects. So, on this (platonist) view, the order of determination is reversed and it is not because of our conceptualisation that certain objects exist or result (that is the artefact view); rather, it is 
because certain objects exist necessarily and mind-independently that we end up always conceptualising these object (provided it is a correct and complete conceptualisation).

So, to conclude, I believe that Dummett's argument from conceptualisation also fails to move his opponent. This is because, if Hale's interpretation is correct and Dummett's argument relies on MEC, then he needs to provide a genuine motivation for adopting MEC, as well as explain away the various counterintuitive consequences. Alternatively, we have suggested that Dummett's own conception could be explained by taking pure abstract objects as a kind of artefact. This interpretation of the argument, however, makes apparent that there is an alternative explanation of the phenomenon of pure abstract objects, one that is both well motivated and clearly accepted by his opponent. Hence, from this perspective of evaluation, Dummett's consideration is not convincing either. Lastly, it is worth noting that if, the argument relies on a conventional account of necessity, then too this is problematic not only because it seems to lead to MEC but also because of various convincing arguments against such an account of necessity, which I cannot cover here. ${ }^{33}$

One remaining question is whether there is a further, alternative interpretation that makes use of Dummett's initial premise 1. In the following section, I will suggest a reading which should not be understood as a direct argument against pure abstract singular terms and their referential ability, but it is meant to exhibit a potential tension. As Dummett writes: "There is, undisputably, a considerable tension between Frege's realism and the doctrine of meaning only in context [i.e. the context principle]: the question is whether it is a headon collision."(Dummett, 1981a, 499).

\section{$5 \quad$ Analysing Dummett's tension}

The aim is to try to develop a prima facie tension within the Neo-Fregean view between the adoption of the context principle on the one hand and platonism on the other. It can be developed by reconsidering premise 1, as Dummett writes:

"The apprehension of reality as having distinct objects is dependent upon the usage of the conceptual apparatus" and thus that "what objects we recognise the world as containing depends on the structure of our language" (Dummett, 1981a, 503).

According to Dummett, this claim follows from the context principle: a language-dependent apprehension of objects flows from the syntactic priority component of the context

principle. Consequently, one can arrive at premise 1 of Dummett's argument because it is through singular terms and linguistic categories in general that we explain and grasp things as objects - our apprehension of objects depends (in parts) on our linguistic framework.

Why might this idea be regarded as being in tension with platonism, i.e. the thought that pure abstract objects exist mind-independently? ${ }^{34}$ One might argue that if certain abstract or pure abstract objects do exist mind-independently, any reference to these objects is a relation to something whose existence and character is viewed as independent

33 See especially (Quine, 1960) and (Quine, 1935). Dummett himself has criticised a certain form of conventionalism in (Dummett, 1959).

34 This is a somewhat crude characterisation of platonism which, however, suffices for our purposes here. For a more detailed discussion of different forms of platonism, see (Linnebo, 2011). 
of our modes of conceiving of them and our modes of talking about them. This, so one might think, is in tension with premise 1 that our apprehension of objects crucially depends on our linguistic framework.

Maybe - but only maybe - it is this alleged basic tension that Dummett discerns within the Neo-Fregean programme. He thinks that such a tension can be avoided for concrete objects, but that it is problematic in the case of pure abstract objects. In the following, I suggest that this worry can be avoided, if it is meant to be a problem for the context principle and platonism. I will then consider whether a similar tension can be discerned within the Neo-Fregean project, if it is re-located in their conception of abstraction principles.

There is an important constraint on whether, according to the Neo-Fregeans, we can apprehend or grasp objects through singular terms as warranted by the context principle: Namely, singular terms have to figure in true sentences. And, it is perfectly compatible with the context principle that our apprehension of reality is, in certain circumstances, incorrect. This can happen, if, to speak crudely, the world does not co-operate and the sentences in virtue of which "apprehension" apparently takes place actually turn out to be false, despite initially good reasons for thinking otherwise. Consequently, we can only legitimately say that there is an object as referent of an abstract singular term if we have sufficient reasons to hold such sentences true - and even then such reasons may be considered defeasible. Furthermore, if the notion of truth for the relevant sentences is sufficiently robust, then there is no tension between our apprehension of the objects being language-dependent on the one hand, and the mind-independent existence of these objects on the other. Hence, there does not have to be a 'head-on collision'.

Nevertheless, and this might be Dummett's underlying worry, the question is whether the Neo-Fregeans are entitled to assume that abstraction principles do involve a notion of truth robust enough for their purpose. That is, the question is whether the idea of stipulating the truth of an abstraction principle - such that they are true by fiatpresupposes a conventional element which cannot involve a notion of truth robust enough. So, one might think that if we arrive at an apprehension of objects purely in virtue of stipulations, then these objects cannot also be regarded as mind-independent. This might be a way to account for a prima facie tension for the Neo-Fregean approach and platonism.

However, if that is what Dummett had in mind, then the tension is wrongly located: It is an issue for a defender of abstraction principles - or implicit definitions in general involving the idea of stipulation; not for a defender of the context principle - the minimal conception and the syntactic priority thesis. It is consistent to adopt both the context principle and platonism yet reject the idea that stipulation is a legitimate method for introducing (robustly) true sentences. Hence, if there is such a tension it has to be resolved by the Neo-Fregeans within a theory of implicit definitions and abstraction principles. ${ }^{35}$

\section{Conclusions}

\footnotetext{
35 For further discussion on the Neo-Fregen conception of implicit definitions and stipulation, see (Hale and Wright, 2000), (Wright, forthcoming), and (Ebert, forthcoming).
} 
In this paper, I hope to have clarified what the content of the Neo-Fregean conception of the context principle is and I have identified four different arguments in Dummett's writing against it. I have argued that none of these arguments are compelling. This is, of course, not to deny that there are other issues raised and also argued for by Dummett (such as impredicativity, or the Caesar problem) that may undermine the viability of the NeoFregean programme. Thus, in this respect my results are modest: I merely claim to have shown that the context principle - in the version outlined here and as used in the NeoFregean programme - is still a viable and compelling principle despite Dummett's arguments. Moreoever, I hope to have identified a basic worry that might have been Dummett's motivation for his opposition to the context principle. However, I believe that this concern should not be regarded as motivating a rejection of the context principle as such; rather, it is a worry that is best levelled against the possibility of stipulating the (robust) truth of certain sentences (such as abstraction principles or implicit definitions in general) - an idea that is also at the heart of the Neo-Fregean project. ${ }^{36}$

\section{References}

Benacerraf, Paul 1973: "Mathematical Truth". Journal of Philosophy 70, 661-80. Reprinted in (Benacerraf \& Putnam, 1983).

Benacerraf, Paul \& Putnam, Hillary 1983: Philosophy of Mathematics. Cambridge University Press, Cambridge, second edition.

Cook, Roy T \& Ebert, Philip A. 2004: "Discussion note: Kit Fine, Limits of Abstraction". British Journal for the Philosophy of Science 55, 791-800.

Dummett, Michael 1959: "Wittgenstein's philosophy of mathematics". The Philosophical Review 68(3), 324-48. Reprinted in (Dummett, 1978).

Dummett, Michael 1978: Truth and other Enigmas. Cambridge, Mass: Harvard Press.

Dummett, Michael 1981a: Frege: Philosophy of Language. Cambridge, Mass: Harvard Press (second edition).

Dummett, Michael 1981b: The Interpretation of Frege's Philosophy. Cambridge, Mass: Harvard Press.

Dummett, Michael 1991: Frege: Philosophy of Mathematics. Cambridge, Mass: Harvard Press.

Dummett, Michael 1998: "Neo-Fregeans: In Bad Company”. In: Matthias Schirn (ed), Philosophy of Mathematics Today, Oxford: Oxford University Press, 369-87.

Ebert, Philip A. forthcoming. "A Framework for Implicit Definitions". In Philip Ebert \& Marcus Rossberg (eds), Abstractionism. Oxford: Oxford University Press.

Field, Hartry. 1989: Science without Numbers. Oxford: Blackwell Publisher.

\footnotetext{
36 I would like to thank Fraser MacBride, Walter Pedriali, Marcus Rossberg, Crispin Wright, and two anonymous referees for comments on earlier versions. Also, I would like to thank the audiences at Bristol, St Andrews, and Stirling for comments that have helped to improve the paper. This work was supported by a grant from the UK Arts and Humanities Research Council: AH/J00233X/1.
} 
Fine, Kit 1975: "Vagueness, Truth and Logic". Synthese 30, 265-300. Reprinted in (Keefe \& Smith, 1997).

Fine, Kit: 2002: Limits of Abstraction. Oxford: Oxford University Press

Frege, Gottlob 1884: Die Grundlagen der Arithmetik. Eine logisch mathematische Untersuchung über den Begriff der Zahl. Breslau: Wilhelm Koebner Verlag.

Hale, Bob 1979: "Strawson, Geach and Dummett on Singular Terms". Synthese 42, 27595.

Hale, Bob 1987: Abstract Objects. Oxford: Basil Blackwell.

Hale, Bob 1994: "Dummett's Critique of Wright's Attempt to Resusciate Frege." Philosophia Mathematica 3, 122-47. Reprinted in (Hale \& Wright, 2001).

Hale, Bob 1995: "Singular Terms (2)". In: Brian McGuiness and Gianluigi Olivieri, G (eds), The Philosophy of Michael Dummett. Dordrecht: Kluwer, 17-44. Reprinted in (Hale and Wright, 2001).

Hale, Bob 1996: Singular Terms (1). In: Matthias (eds), Frege: Importance and Legacy. Berlin, New York: Walter de Gruyter, 438-57. Reprinted in (Hale \& Wright, 2001).

Hale, Bob 2000: "Reals by Abstraction". Philosophia Mathematica 8, 100-123.

Hale, Bob \& Wright, Crispin 2000: "Implicit definition and the a priori". In: Paul Boghossian \& Christopher Peacocke, (eds), New Essays on the A Priori. Oxford: Oxford University Press, 286-319. Reprinted in (Hale \& Wright, 2001).

Hale, Bob \& Wright, Crispin 2001: The Reason's Proper Study: Essays towards a NeoFregean Philosophy of Mathematics. Oxford: Oxford University Press.

Hale, Bob \& Wright, Crispin 2002: "Benacerraf's dilemma revisited". European Journal of Philosophy 10(1), 101-129.

Keefe, Rosanna \& Smith, Peter 1997: Vagueness: A Reader. Cambridge, Mass: MIT Press.

Linnebo, Øystein 2013: "Platonism in the philosophy of mathematics". In Ed N. Zalta (ed), The Stanford Encyclopedia of Philosophy.

MacBride, Fraser 2003: "Speaking with Shadows: A Study of Neo-Fregeanism". British Journal for the Philosophy of Science 54, 103-63.

Quine, Willard Van Orman 1935: "Truth by Convention. In: Filmer Northrop \& Mason Gross (eds), Philosophical Essays for Alfred North Whitehead. New York: Longmans. Reprinted (Quine, 1966).

Quine, Willard Van Orman 1960: "Carnap on Logical Truth". Synthese 12(4), 350-74. Reprinted in (Quine, 1966).

Quine, Willard Van Orman 1966: The Ways of Paradox. New York: Random House.

Rosen, Gideon 1993: "The Refutation of Nominalism”. Philosophical Topics 21, 149-86. 
Shapiro, Shapiro 1998: "Logical consequence: Models and modality". In: Matthias Schirn, (ed), Philosophy of Mathematics Today. Oxford: Oxford University Press. 131-156.

Wetzel, Lisa 1990: “Dummett's Criteria for Singular Terms”. Mind 99, 239-64.

Williamson, Timothy 1988: "Review of B. Hale, 1987, Abstract Objects". Mind 98, 487-90.

Wright, Crispin 1983: Frege's Conception of Numbers as Objects. Aberdeen: Aberdeen University Press.

Wright, Crispin 1995: "Critical Notice of Michael Dummett's Frege: Philosophy of Mathematics". Philosophical Books. Reprinted in (Schirn, 1998) and in (Hale \& Wright, 2001).

Wright, Crispin 1998a: "On the (harmless) impredicativity of Hume's principle". In Matthias Schirn (ed), Philosophy of Mathematics Today. Oxford: Oxford University Press, 339-368. Reprinted in (Hale \& Wright, 2001).

Wright, Crispin 1998b: "Why Frege did not deserve his Granum Salis: a note on the paradox of the "concept horse"'. Grazer Philosophische Studien 55, 239-63. Reprinted in (Hale and Wright, 2001).

Wright, Crispin forthcoming: "Abstraction and Epistemic Entitlement: On the Epistemological Status of Hume's Principle. In Philip A. Ebert \& Marcus Rossberg (eds), Abstractionism. Oxford: Oxford University Press. 